\title{
Teleseismic analysis of the 1990 and 1991 earthquakes near Potenza
}

\author{
Göran Ekström \\ Department of Earth and Planetary Sciences, Harvard University, Cambridge, MA, U.S.A.
}

\begin{abstract}
Analysis of the available teleseismic data for two moderate earthquakes near the town of Potenza in the Souththe larger, 5 May 1990, earthquake ise strike-slip faulting on a plane oriented approximately east-west. Only version methods, and is earthquake is sufficiently large for analysis by conventional teleseismic waveform inment. The focal mechanism and seismic moment of the followed 11 seconds later by the main release of mocomparison of its 15-60 s period surface mechanisms for the two approximately $18 \%$ that of the 1990 nd to be very similar. The 1991 earthquake has a scalar moment that is recorded at regional distance, shows that ments, suggesting that the stress drop for the 1991 trace amplitudes is smaller than the ratio of scalar mo-
\end{abstract} Key words earthquakes - Apennines - stress
drop

\section{Introduction}

Ten years after the devastating 23 November 1980 Irpinia $\left(M_{W}=6.9\right)$ earthquake, a moderate $\left(M_{L}^{\mathrm{ING}}=5.2, m_{b}{ }^{\text {NEIC }}=5.3\right)$ event on 5 May 1990 occurred approximately $40 \mathrm{~km}$ east of the southern end of the 1980 aftershock zone, causing damage in the nearby town of Potenza. The 5 May 1990 event generated a large number of aftershocks, which were located by Azzara et al. (1993) using data from a temporarily deployed seismic network. The aftershocks show a distinct east-west trend (fig. 1a), and appear to define a roughly vertical plane (fig. 1b). Approximately one year later, on 26 May 1991, another moderate $\left(m_{b}{ }^{\text {NEIC }}=5.1\right)$ earthquake struck the same area, causing additional minor damage in the Potenza area.

Azzara et al. (1993) point out three unusual aspects of the 1990 Potenza sequence. First, the fault area outlined by the aftershocks extends approximately $20 \mathrm{~km}$ in length and 10 $\mathrm{km}$ in depth, making it significantly larger than what is expected for a $M_{L}=5.2$ earthquake. Second, the aftershocks were concentrated between 15 and $25 \mathrm{~km}$ depth, which is significantly deeper than other well determined focal depths in the central and southern Apennines. Third, the vertical dip of the plane defined by the aftershocks, and the strike-slip focal mechanism determined from the mainshock $P$ wave first motions (Iannaccone et al., 1990), are also unusual for the Apennines, where most moderate and large earthquake show normal faulting, consistent with the extensional tectonics of the region (e.g., Westaway and Jackson, 1987). The closeness in time of the Potenza earthquakes with respect to the 1980 Irpinia earthquake, and the spatial proximity to the southern termination of the Irpinia earthquake fault (Pantosti and Valensise, 1990) add to the interesting aspects of these events.

The 5 May 1990 mainshock was previously analyzed by the Harvard group (Dziewonski et al., 1991) in the routine Centroid-Moment 
Tensor (CMT) analysis of global seismicity. The focal mechanism determined in that study is strike-slip, but with nodal planes rotated approximately $25^{\circ}$ with respect to the solution of Iannaccone et al. (1990). Additionally, the published CMT solution has a large moment $\left(M_{W}{ }^{\mathrm{CMT}}=5.8\right)$ with respect to the reported magnitudes, and an unusually large centroid time shift (14 s), suggesting a slow or complex source process. These discrepancies and unusual observations, in conjunction with the possible significance of the Potenza earth- quakes for understanding the seismic hazard and tectonic activity in the Southern Apennines, motivate further study of these events. The purpose of this paper is to reevaluate the teleseismic observations and CMT solution for the 1990 earthquake in an attempt to clarify the apparent discrepancies in fundamental earthquake parameters just mentioned. In addition, I review the teleseismic observations for the 1991 earthquake, and provide estimates of its moment and focal mechanism by a quantitative comparison with the 1990 earthquake.

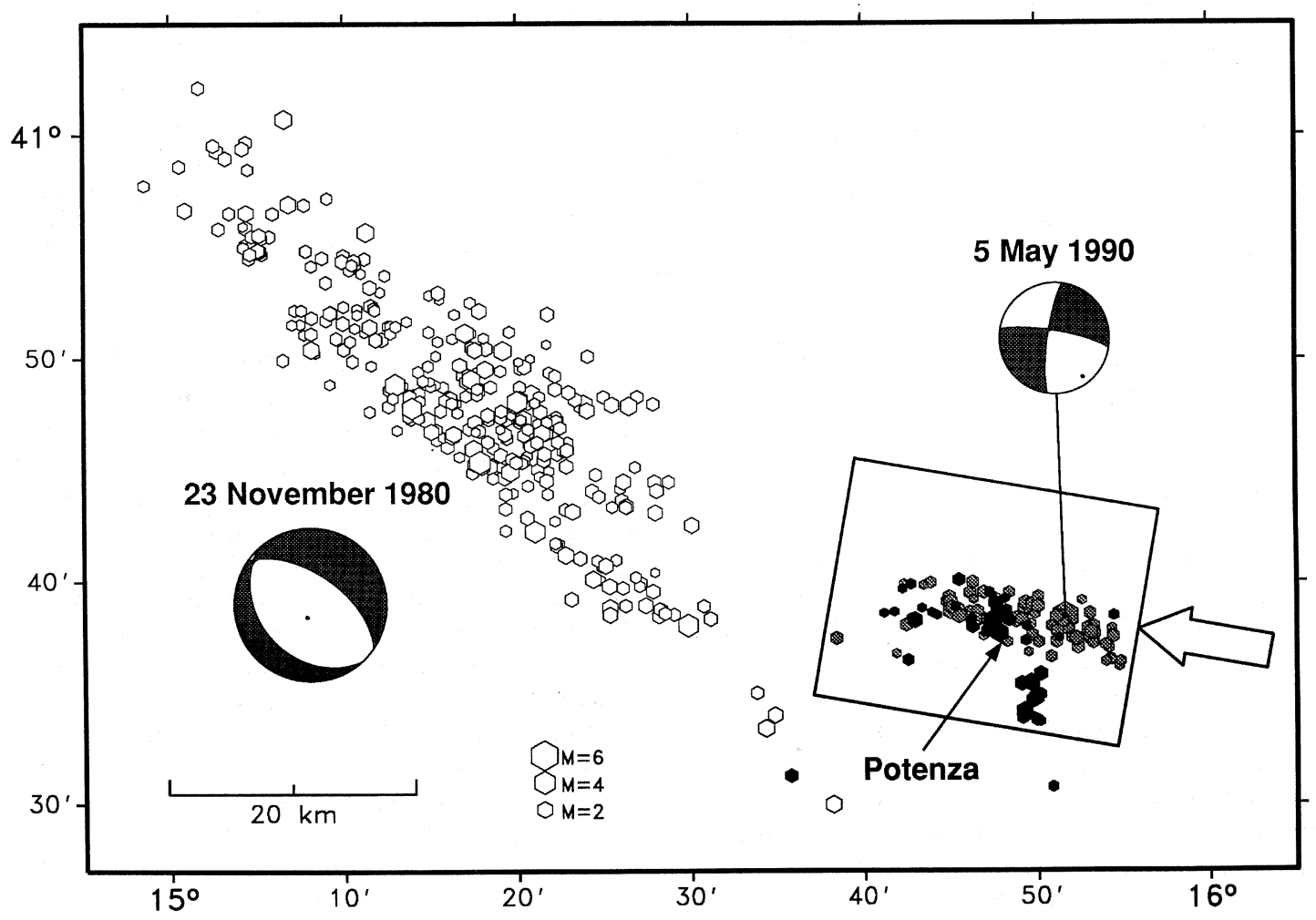

Fig. 1a. Map view of the hypocentral area of the Potenza earthquakes. Open hexagons show the aftershocks of the 1980 Irpinia earthquake (Amato and Selvaggi, 1993). Gray hexagons show the aftershocks of the 1990 Potenza earthquake (Azzara et al., 1993) and black hexagons show the 1991 aftershocks (A. Amato, personal communication, 1994). Only events with a vertical location error of less than $3.0 \mathrm{~km}$ and horizontal error of less than $1.5 \mathrm{~km}$ are plotted. The double couple mechanism for the 1980 Irpinia earthquake (Ekström et al., 1987), and the preferred double couple mechanism for the 1990 Potenza event (this study) are shown in lower hemisphere projection. The box and arrow show the horizontal extent and viewing direction used in the cross section in fig. $1 \mathrm{~b}$. 


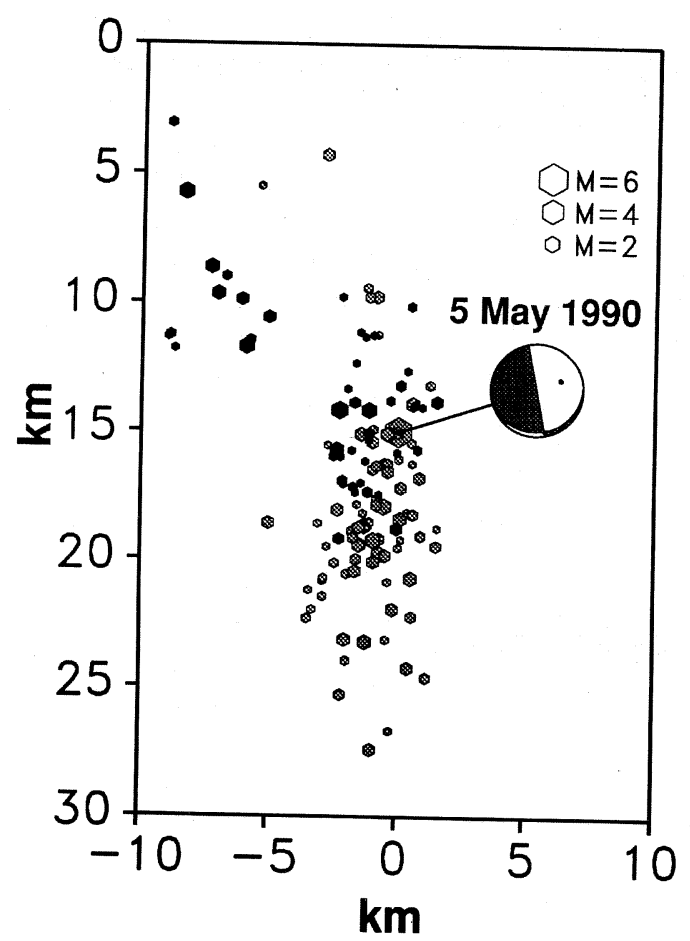

Fig. 1b. Cross section showing the vertical extent of the aftershocks, when viewed in the direction of the east-west striking nodal plane. Symbol shading as in fig. 1a. The focal mechanism of the 1990 mainshock is shown in back hemisphere projection.

\section{The 5 May 1990 Potenza earthquake}

The main reason for the conflicting results for the 5 May 1990 mainshock is undoubtedly that the earthquake on closer inspection is seen to consist of a foreshock followed $11 \mathrm{~s}$ later by the larger mainshock. Initially only one hypocenter, based on the $P$ arrivals from the smaller foreshock, was reported in regional and teleseismic catalogs. Magnitude readings for the initial shock were, however, contaminated by the second and larger event. Catalog locations and magnitudes for the foreshock and mainshock are listed in table I. The foreshock and mainshock can also be distinguished on some regional recordings. Figure 2 shows clearly the larger $P$ wave onset of the second event on a record from the broadband MEDNET station AQL (L'Aquila). The main moment release in the earthquake is associated with the mainshock; this provides an explanation for the large CMT centroid time shift reported by Dziewonski et al. (1991), who associated the CMT solution with the event that is now known to be the foreshock.

In order to verify and assess the reliability of the earlier CMT results, I recalculate the CMT solution. I use the same algorithm as Dziewonski et al. (1991), but include additional data from GEOSCOPE stations, and employ a recent laterally heterogeneous model of Earth structure (Dziewonski et al., 1992) in the calculation of synthetic seismograms. The CMT algorithm matches observed long-period ( $\mathrm{T}>45 \mathrm{~s})$ seismograms, which contain all body wave phases that arrive before the fundamental mode surface waves, with synthetic seismograms. An iterative inverse procedure, which minimizes the misfit between observed and model seismograms, leads to an estimate of the moment tensor elements and a centroid location, which together provide the point source parameters which best predict the observed waveforms. The shift of the centroid from the initial hypocentral location is influenced not only by the true location of earthquake moment release, but also by deviations of the true Earth from the elastic model used in the calculation of synthetic seismograms. In general it is not possible to attach any significance to small $(\leq 25 \mathrm{~km})$ shifts in the epicentral location, while shifts of $10 \mathrm{~km}$ or more in depth usually are significant.

I performed several experiments in which subsets of the data were deleted, and the depth and epicenter were held fixed at the initial locations. The strike-slip character of the solution, and a scalar moment of $4-5 \times 10^{24}$ dyne$\mathrm{cm}\left(M_{W}=5.7\right)$ are robust results of the various inversions. The dip and rake angles of the double couple solution can vary by $\pm 10^{\circ}$ in different inversions, but the strikes of the two nodal planes are more robust and only vary by a few degrees. The scalar moment that I obtain is ap- 
Table I. Hypocentral coordinates.

\begin{tabular}{lrrr}
\hline \hline & $\begin{array}{c}\text { 5 May 1990 } \\
\text { (foreshock) }\end{array}$ & $\begin{array}{c}\text { 5 May 1990 } \\
\text { (mainshock) }\end{array}$ & 26 May 1991 \\
\hline Latitude (ING) & 40.64 & & 40.7 \\
Latitude (NEIC) & 40.744 & 40.775 & 40.730 \\
Longitude (ING) & 15.86 & & 15.8 \\
Longitude (NEIC) & 15.853 & 15.766 & 15.765 \\
Depth (NEIC) & 13.0 & 10.0 & 8.0 \\
Depth (ING) & 15.0 & & 5.0 \\
Depth (this study) & & $9-13$ & 5.3 \\
$m_{b}$ (ISC) & 5.2 & 5.1 & 5.1 \\
$m_{b}$ (NEIC) & 4.6 & 5.3 & 4.8 \\
$M_{S}$ (NEIC) & & 5.4 & 5.2 \\
$M_{W}$ (this study) & $\leq 5.0(?)$ & 5.7 & \\
\hline
\end{tabular}

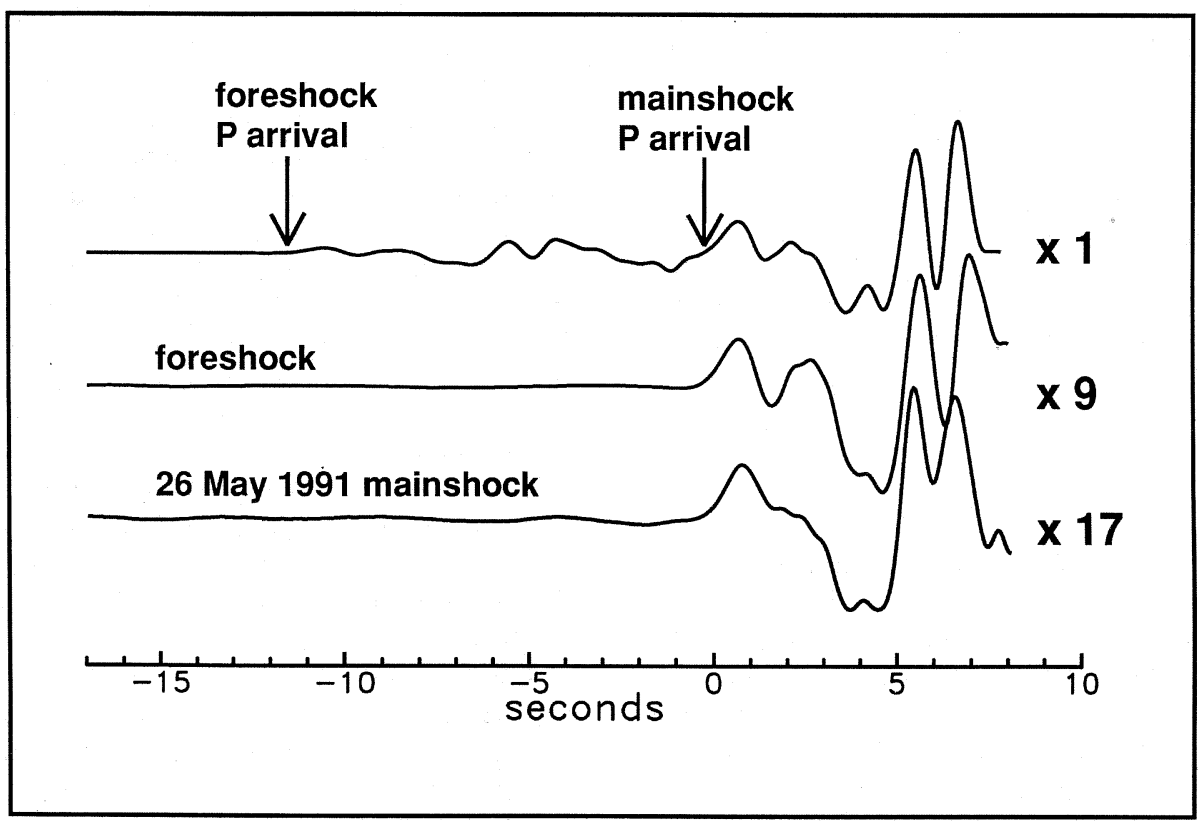

Fig. 2. Comparison of $P$ waves from Potenza earthquakes recorded at the MEDNET station AQL at $270 \mathrm{~km}$ distance. The traces are vertical component records filtered to displacement between $2 \mathrm{~Hz}$ and $20 \mathrm{~s}$, and are aligned on the $P$ wave arrival. The top trace is aligned on the 5 May 1990 mainshock arrival. The foreshock arrival is indicated with an arrow. The middle trace shows the foreshock $P$ wave enlarged by a factor of 9 , and shifted $11 \mathrm{~s}$ to align it with the mainshock trace above. The bottom trace shows the $P$ wave for the 26 May 1991 earthquake, enlarged by a factor of 17. 
Table II. Source parameters ${ }^{\mathrm{a}}$.

\begin{tabular}{lrr}
\hline & \multicolumn{1}{c}{ CMT } & VBB \\
\hline$M_{r r}$ & -0.135 & -0.068 \\
$M_{\theta \theta}$ & -0.002 & -0.098 \\
$M_{\phi \phi}$ & 0.137 & 0.166 \\
$M_{r \theta}$ & 0.041 & 0.083 \\
$M_{r \phi}$ & -0.035 & 0.059 \\
$M_{\theta \phi}$ & -0.402 & -0.428 \\
$M_{0}$ & 0.41 & 0.46 \\
$M_{W}$ & 5.7 & 5.7 \\
Strike & $95^{\circ}$ & $280^{\circ}$ \\
Dip & $88^{\circ}$ & $79^{\circ}$ \\
Rake & $175^{\circ}$ & $-169^{\circ}$ \\
Depth & $15.0 \mathrm{~km}$ & $10.6 \mathrm{~km}$ \\
\hline
\end{tabular}

${ }^{\mathrm{a}}$ Moment values are in units of $10^{25}$ dyne-cm.

proximately $30 \%$ smaller than reported by Dziewonski et al. (1991), who held the source depth fixed at $26 \mathrm{~km}$. In my preferred solution, the CMT source location is held fixed at the hypocenter reported by Azzara et al. (1991) $\left(40.64^{\circ} \mathrm{N}, 15.86^{\circ} \mathrm{E}\right.$ and $15 \mathrm{~km}$ depth). The moment tensor and its associated «best double couple» solution are given in table II.

While high frequency and broadband seismograms for the mainshock are contaminated by the preceding foreshock, it is still possible to extract some additional information about the earthquake from teleseismic $P$ waveforms. I analyzed the earthquake using the very broad band method of Ekström (1989) in an attempt to better constrain the focal depth and the duration of the rupture process. In this algorithm, teleseismic broadband $(100 \mathrm{~s}-1 \mathrm{~Hz}) P$ wave displacement pulses are modeled using synthetic waveforms calculated using ray theory. The parameters which are allowed to vary are the point source moment tensor, the focal depth and the time history of moment release. The results of the CMT analysis are included as weak constraints on the moment tensor, and stabilize the inversion. The algorithm is aimed at producing results which are consistent with both the broadband $P$ wave pulses and the long-period CMT observations.
The main source of uncertainty in modeling the $P$ waves from the mainshock stems from errors in the timing of the $P$ wave onset. For strike-slip earthquakes, teleseismic arrivals are often nodal and difficult to identify. These problems are exacerbated for the 5 May 1990 mainshock, due to the interference of the foreshock. After several experiments, arrival times were selected for 8 stations with acceptable waveforms, and the inversion produces reasonable fits to the data. The best fitting source model is shown in fig. 3. The largest amplitudes in the waveforms are the surface reflected $p P$ and $s P$ phases, and the depth estimate of $10.6 \mathrm{~km}$ is primarily constrained by the relative delay of these phases with respect to the direct $P$ arrival. Since the direct arrival is poorly modeled, and the $P$ onset is ambiguous at most stations, the depth estimate is uncertain. A source depth between 9-13 km for the main release of moment appears to be required by these data. The focal mechanism of the combined analysis differs from the CMT results in that the east-west nodal plane dips steeply to the north instead of steeply to the south, but with the limited quality of the data, and uncertainties in the synthetic waveforms, this difference of $13^{\circ}$ in the dip angle is probably contained within the uncertainties of the results. The source duration of $5 \mathrm{~s}$ is not unusual for earthquakes of this size (Ekström et al., 1992). Additional details of the source time function cannot be resolved with the available teleseismic data set. I prefer the very broad band solution over the CMT results since it satisfies both long-period and broadband data as well as can be expected, considering the data distribution and quality. The very broad band solution also contains a smaller non-double couple component (Dziewonski and Woodhouse, 1983) $(\epsilon=0.08)$ than the CMT solution $(\epsilon=0.26)$, which sometimes indicates a tectonically more plausible solution. The very broad band results are listed in table II.

\section{The 26 May 1991 Potenza earthquake}

From inspection of the seismograms generated by the 26 May 1991 earthquake it ap- 


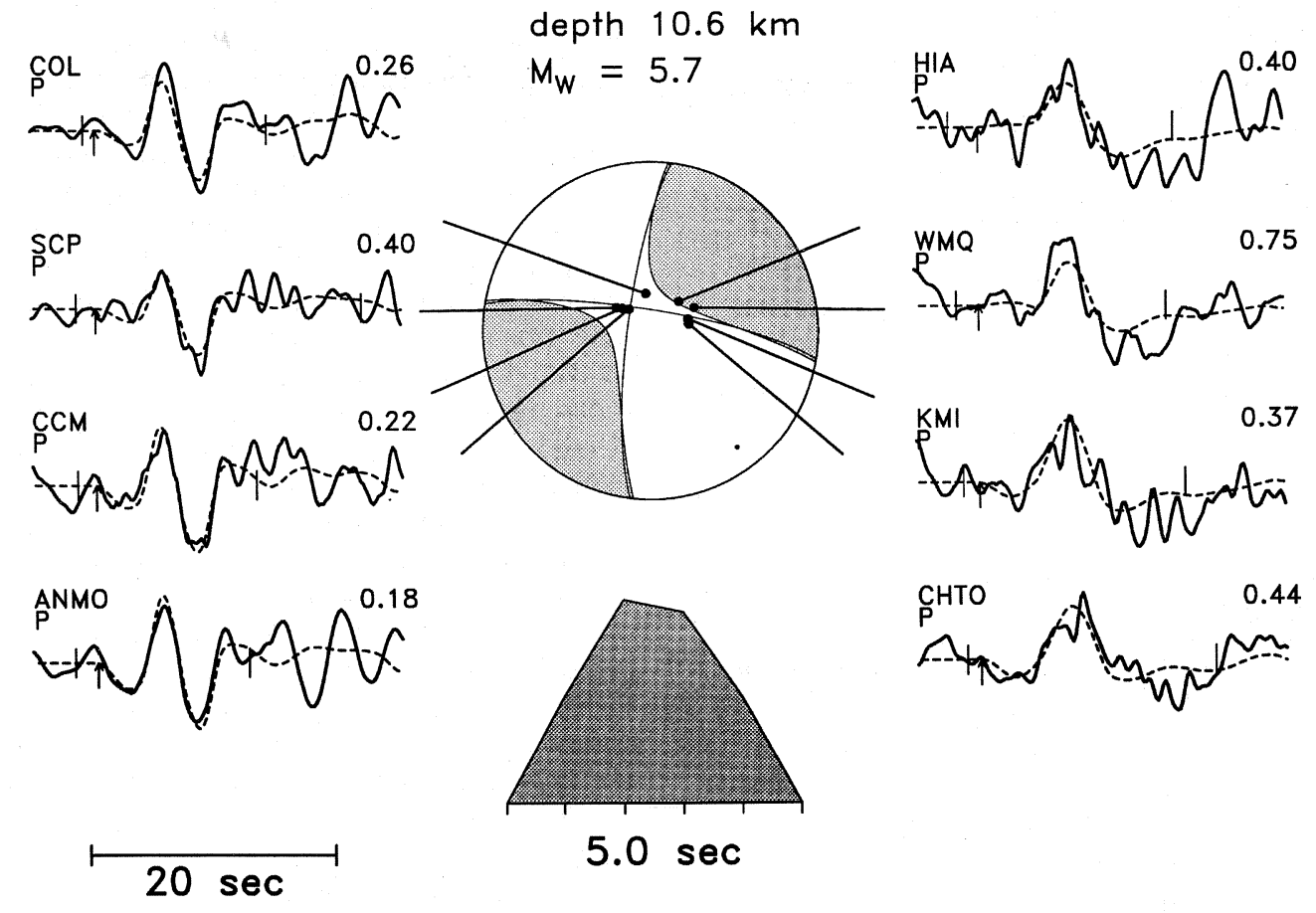

Fig. 3. Broadband waveform inversion results for the 5 May 1990 Potenza main shock. Solid lines are the observed broadband waveforms, and dashed lines are the corresponding synthetic waveforms. The maximum amplitude is indicated in micrometers. The small arrow indicates the $P$ wave arrival, and the brackets show the portion of the waveform that was used in the inversion. The shading in the focal mechanism show the $P$ wave radiation pattern of the complete moment tensor, and the thin lines show the nodal lines of the best double couple. The source time function is also shown.

peared that the event would be sufficiently large to be analyzed using the CMT method. Unfortunately, however, a larger event in the Talaud Islands 30 min earlier generated waves which interfere with those of the Potenza event at many stations, and the CMT analysis did not produce stable results. In order to provide an estimate of the source geometry and the scalar moment of the 26 May 1991 earthquake, I instead compare the teleseismic Love and Rayleigh waves from the event with those generated by the larger 5 May 1990 earthquake.

For shallow earthquakes, surface waves in the period band 15-60 s generate large arrivals, with high signal-to-noise ratios, at teleseismic distances. The phase and amplitude of these waves are difficult to model deterministically, due to heterogeneous upper mantle and crustal structure which produce complex propagation effects. However, the hypocenters for the 1990 and 1991 Potenza earthquakes are separated by $15 \mathrm{~km}$ or less, and the effects of path differences should be minimal when we compare surface wave recordings at the same station. Figure 4 shows a comparison of Love and Rayleigh waves for the two events recorded at 
the station KEV (Kevo, Finland) at $30^{\circ}$ distance. When the records are scaled by arbitrary factors, the similarities are remarkable. The scaling factor required at $\mathrm{KEV}$ is approximately 0.18 for all three components of motion (vertical, longitudinal, and transverse). In order to quantitatively compare the Potenza events, I cross-correlate the Rayleigh and Love waves for the two earthquakes at each station that recorded both event. A small relative time shift is allowed for in the correlation, to account for a delay introduced by the slightly different epicentral locations, but this shift is not greater

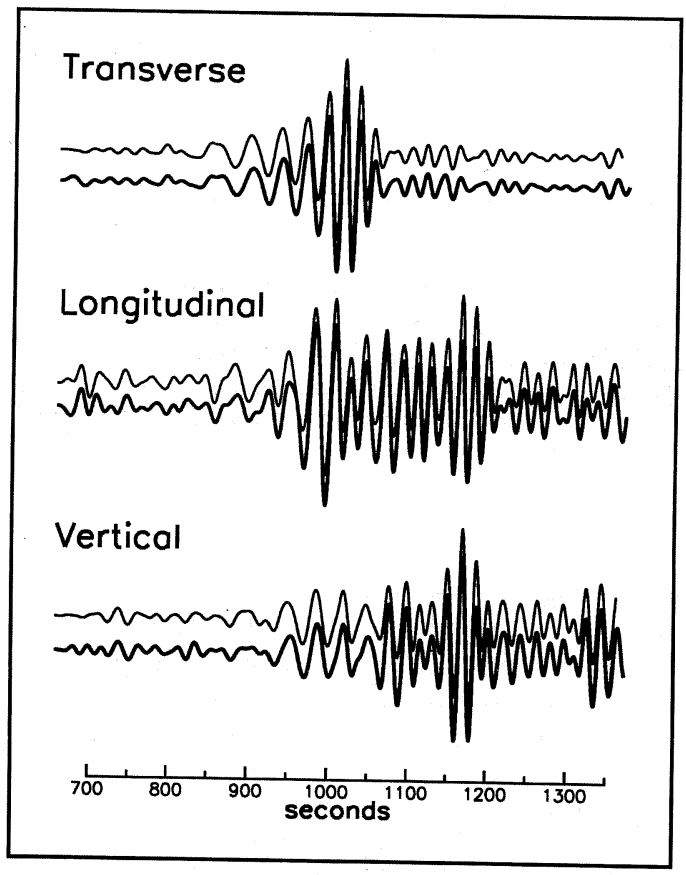

Fig. 4. Surface waves from the 5 May 1990 and 26 May 1991 Potenza mainshocks recorded at KEV in Finland at $30^{\circ}$ distance. Traces 1,3 , and 5 from the top show transverse, longitudinal, and vertical components of motion for the 1990 event. Traces 2, 4, and 6 show the corresponding traces for the 1991 event. The 1990 waveforms have been scaled by a factor of 0.18 to best match the amplitudes of the 1991 waveforms. The seismograms have been filtered with a lowpass corner at $18 \mathrm{~s}$ and a highpass corner at $60 \mathrm{~s}$. than a few seconds. Figure 5 shows the azimuthal distribution of the relative amplitudes of the 26 May 1991 seismograms with respect to those of the 5 May 1990 event. The main observation is that for both Rayleigh and Love waves, and at different azimuths, the required scaling factor is almost constant. The fact that only a constant factor is needed to bring the two radiation patterns into agreement indicates that the 26 May 1991 event had a focal mechanism very similar to the 5 May 1990 event, and a scalar moment approximately $18 \%$ that of the larger event, $0.8 \times 10^{24}$ dyne-cm.

The similarity in focal mechanisms is consistent with the aftershock patterns shown in fig. 1. Most of the 1991 aftershocks fall along the roughly vertical plane defined by the 1990 sequence, although more events are at shallower depths. A cluster of events which lie on a plane oriented at $90^{\circ}$ with respect to the eastwest plane developed two weeks into the 1991 aftershock sequence, and are possibly related to motion on a conjugate fault.

\section{Discussion}

The $280^{\circ}$ strike of one of the nodal planes in the preferred solution for the 1990 mainshock agrees very well with the strike of the aftershock distribution of Azzara et al. (1993) shown in fig. 1. A close to vertical dip for the east-west striking plane is also consistent with the aftershock data. The $200 \mathrm{~km}^{2}$ area covered by the aftershocks, which is unusually large for a $M_{L}=5.2$ earthquake, is consistent with the teleseismic moment estimate $\left(M_{W}=5.7\right)$, when compared with earthquakes in other areas (Kanamori and Anderson; 1975). The depth for the Potenza earthquake is not well constrained, but appears from teleseismic data to be centered around $11 \mathrm{~km}$. This is partly consistent with the great depth extent of the aftershocks, even though the aftershock data can be interpreted to show a deeper center of the fault rupture. A remaining inconsistency exists between the small local magnitude with respect to the scalar moment; it is possible that the regional seismic radiation from the 1990 Potenza earthquake was depleted in high-frequency energy 


\section{Rayleigh waves}

Average amplitude ratio: 0.18

\section{Love waves}

Average amplitude ratio: 0.18
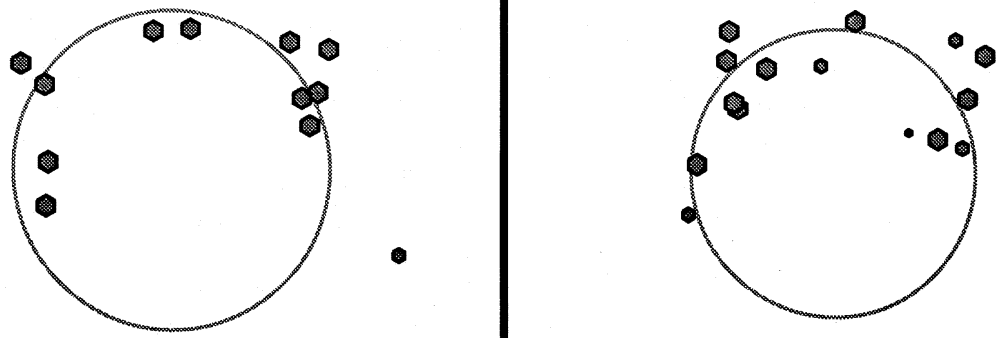

Fig. 5. Azimuthal plot of the relative radiation amplitudes for the 1990 and 1991 Potenza main shocks at different stations. The radial distance of a symbol from the center of each circle is proportional to the scaling factor required to maximize the correlation between seismograms for the two events. The smaller symbols indicate correlations with larger uncertainties. Both Love and Rayleigh wave amplitudes are different by a factor of 0.18 , indicating very similar focal mechanisms for the two events, and a scalar moment for the 1991 event of approximately $0.8 \times 10^{24}$ dyne-cm $\left(M_{W}=5.2\right)$.

due to a low stress drop or, possibly, to an unusual source depth.

While it is possible to constrain the seismic moment of the 26 May 1991 event to be approximately $18 \%$ of the 1990 mainshock moment, it is more difficult to estimate the size of the 1990 foreshock, in particular since we do not know that the foreshock had the same focal mechanism as the mainshock. Indeed, the focal mechanism of Iannaccone et al. (1990) has a strike closer to $300^{\circ}$, approximately $20^{\circ}$ different from my preferred solution. Note, however, that the initial part of the $P$ waves in fig. 2 are very similar, and that at least a crude relative measure of source size is reflected in the scale factor needed to bring the amplitudes of the seismograms into agreement. The initial portion of the foreshock $P$ wave is smaller by a factor of 0.11 with respect to the mainshock, suggesting that the scalar moment of the foreshock is smaller by at least this factor, since differences in scalar moments usually are larger than those of higher frequency wave amplitudes. This follows from the falloff in the source spectrum, and standard scaling of the corner frequency (e.g. Aki, 1967).

The preceding argument for the foreshock and mainshock leads to an interesting observation with respect to the 1991 earthquake. In fig. 2, the amplitude of the $1991 P$ wave is smaller than that of the 1990 mainshock by a factor of 0.06 while we have seen that the long-period moment is smaller by a factor of 0.18 . From simple source scaling arguments we would instead expect the amplitude ratio to be greater than 0.18 at shorter periods. This suggests that the 1991 event is depleted in higher frequency radiation with respect to the 
1990 mainshock. Clearly, these qualitative observations could be investigated further using the existing local and regional recordings for this event, and spectral measurement techniques. Here I conclude only that these observations, from a single MEDNET station, suggest that the 1991, and possibly also the 1990 , Potenza earthquakes may have had unusually low stress drops.

\section{Acknowledgements}

I thank Alessandro Amato for helping me get access to the aftershock location data and Sue Hough for encouraging me to take a closer look at the seismograms for the 1991 earthquake. This research was supported by the grant EAR92-19361 from the U.S. National Science Foundation.

\section{REFERENCES}

AKI, K. (1967): Scaling law of seismic spectrum, J. Geophys. Res., 72, 1217-1231.

Amato, A. and G. SelvagGi (1993): Aftershock location and $P$-velocity structure in the epicentral region of the 1980 Irpinia earthquake, Ann. Geofis., 36, 3-15.

Azzara, R., A. Basili, L. Beranzoli, C. Chiarabba, R. Di Giovambattista and G. Selvaggi (1993): The seismic sequence of Potenza (May 1990), Ann. Geofis., 36, 237-243.
Dziewonski, A.M. and J. H. Woodhouse (1983): An experiment in systematic study of global seismicity: centroidmoment tensor solutions for 201 moderate and large earthquakes of 1981, J. Geophys. Res., 88, 32473271.

Dziewonski, A.M., G. Ekström, J. H. Woodhouse and G. ZWART (1991): Centroid-moment tensor solutions for April-June, 1990, Phys. Earth Planet. Inter., 66, 133143.

Dziewonski, A.M., G. Ekström and M. P. SAlganik (1992): Centroid-moment tensor solutions for July-September, 1991, Phys. Earth Planet. Inter., 72, 1-11.

Ekström, G., A.M. Dziewonski and J. H. Woodhouse (1987): Centroid-moment tensor solutions for the 51 IASPEI selected earthquakes, 1980-1984, Phys. Earth Planet. Inter., 47, 62-66.

EкsтRöm, G. (1989): A very broadband inversion method for the recovery of earthquake source parameters, Tectonophysics, 166, 73-100.

Ekström, G., R.S. Stein, J.P. Eaton and D. EberhartPhILliPs (1992): Seismicity and geometry of a 110-kmlong blind thrust fault, 1. The 1985 Kettleman Hills earthquake, J. Geophys. Res. 97, 4843-4864.

Iannaccone, G., R. Romeo, G. Tranfaglia, L. Errico, E. Lentini, P. Bernard, A. Deschamps and G. Patau (1990): Analisi della sequenza sismica di Benevento (aprile-maggio 1990), in Atti del $9^{\circ}$ Convegno Nazionale GNGTS (submitted).

KANAMORI, H. and D.L. ANDERSON (1975): Theoretical basis for some empirical relations in seismology, Bull. Seismol. Soc. Am., 65, 1073-1095.

Pantosti, D. and L. VAlensise (1990): Faulting mechanism and complexity of the 23 November, 1980, CampaniaLucania earthquake inferred from surface observations, J. Geophys. Res., 95, 15319-15341.

Westaway, R. W. C. and J. JACKSON (1987): The earthquake of 1980 November 23 in Campania-Basilicata (Southern Italy), Geophys. J. R. Astron. Soc., 90, 375-443. 